\title{
1. Cosmopolitan irony: pluriversality and perspective
}

\section{A SOCIOLOGY OF PERSPECTIVE}

We live in a world that espouses conceptual singularities as shortcuts to 'truth' - which is why we see people driving airplanes into buildings full of thousands of other people working for or admiring the icons of First World consumerist phantasmagorias as tourists. The capacity (and skill) to examine such tragedies of symmetrical somnambulism in ironic styles is usually judged against a standard of 'soberness', without actually questioning what ironic style entails in context. The willingness to interrogate the moral complexities of such cultural landscapes, which become dominated by 'inherited verities' and 'singularities' (Rapport, 2003, p.46), can only survive if the individual freedom to question them is recognised as a right. Unfortunately, such ironic styles of seeing and narrating the world can also offend and generate friction - for, 'having rights' comes with having responsibilities, including that to respect others. Though in itself an epistemological universal, 'perspective' exists in at least as many forms as the communities that humans create to host their values and norms. Originating in the medieval perspectiva, the science of optics, from the Latin verb perspicere (per: 'through' + specere: 'to look at closely') (Concise Oxford English Dictionary, 2011, p.1071), perspective is just another word for episteme (epistēme), which has an identical meaning and refers to epistemological comprehension. We get to know things well - the etymological composition of episteme (istamai: to stand and metaphorically master + epi: on top of a surface) - but always conditionally: upon circumstances, strategies and the tools afforded to us in our cultural, social and physical environments. We should not forget to include 'rights' and 'responsibilities' in this heavy package of prerequisites - two rather ambivalent terms also determined by context.

This book is a study of the friction that perspectives generate in cross-cultural contexts. My interdisciplinary spyglass is placed on these perspectives' cultural substance, as this manifests itself in different communities' ability to question or enhance individuality as a gateway to the creation of collective 'life projects'. These ontological projects support such cosmopolitan values 
as those we find in the cultures of travel, artmaking and tourism, which are ridden with class, race, ethnicity and gender symbolisms pertaining to the right to mobility (Cresswell, 2006; Korstanje, 2018a; Sheller, 2018). Undoubtedly, contemporary travel reflects 'differential mobility empowerments' (Hannam et al., 2006, p.3), involving a spectrum of voluntary to involuntary or coerced mobilities, which are normalised or criminalised respectively (Salazar and Schiller, 2013). Although definitions - or 'perspectives' - of these activities are not universal, the ways they are experienced can point to meeting points and shared cultural horizons. I find theories of cosmopolitanism pedagogically useful when they have context, thus demonstrating their cultural applicability. Bouncing between theory and context helps one consider the limitations and potentialities of 'cosmopolitan irony' as a cultural genre, which is often entwined with political superimpositions on its substance. Although my 'cosmopolitan irony' draws up to a point on Turner's (2002) recognition that an ironic stance towards one's own culture is intertwined with their commitment to equality, reflexivity and openness, I am particularly interested in the ways ironic aesthetics produce ambivalent ethical stances. I am specifically interested in examining whether ethics and aesthetics always form a unity and continuum. I pay attention to the consequences of their separation, which do not have to be always negative. To me 'ethics' refers to habitual engagement with everyday events in various conscious and unconscious ways that are productive (generative and creative) and reproductive of realities. Irony often errs on conscious creativity - a quality for which mobile cosmopolitan ironists are treated with contempt by immobile rooted subjects.

I will commence my investigation by refracting my theoretical analysis through a particular instance of 'cosmopolitan friction'. This uses the content and multiple contexts of reception and consumption of a recent award-winning American film, Joker (2019, director Todd Phillips, screenwriters Todd Phillips and Scott Silver). Irony and art are good friends and cosmopolitanism thrives on audio-visual mobilities which involve variations of physical/embodied and cognitive/virtual travel, so this example will join other similar ones in subsequent chapters and should not be seen as the book's focus. I opted to start with this example because its core theme is the relationship between ethics and aesthetics in a world of divisions and inequalities. Based on two famous DC Comics characters, the Joker and Batman, the story provides a potential narrative of their origins, as well as their associations with cosmic ideas of good and evil, transgression, justice and fairness. Set in 1981, the cinematic plot follows an aspiring stand-up comedian and party clown, Arthur Fleck (Joaquin Phoenix), who lives with his mother in the crime-ridden Gotham City. Suffering from a medical disorder causing uncontrolled laughter at inappropriate times, Arthur depends on social services to receive his medication and remain functional and employable. The withdrawal of these services, the 
loss of his precarious job because he is found to carry a gun, a series of revelations about Arthur's family background and the continuous failure to achieve recognition in his profession, drive Arthur to insanity and crime. After murdering some harassing businessmen, his mother for lying to him about the identity of his father, his colleague for giving him the gun for self-protection and his favourite celebrity, Murray Franklin (Robert de Niro) on air from resentment, Arthur finds himself elevated to an icon of revolution by the disenfranchised and impoverished Gothamites. His dream to make people laugh and happy has turned into a social nightmare and Arthur himself is locked into a mental asylum, where he continues to kill and laugh at his own jokes.

The film itself might be classified as an artistic critique of American inequality. However, this is not a film studies book, nor does it examine cinematic texts as such. A film sociology can use particular films as analytical conduits to develop theoretical models with which to study society; and a focus on their atmospheric potential does not produce a geographical account of them, only one focusing on the politics of place. I follow the Joker's multiple discursive networks (as these are generated in new media sites and through my own interpretation of their content) to examine the persistence or suppression of ironic creativity across different temporal and spatial contexts. As a style, irony necessitates a 'displacement', allowing individuals to be habitually deconstructed and reconstructed (Bourdieu, 1977, p.90), a form of 'alienation' standing at heart of creative renewal and the moment of 'arriving [at] home' (Kateb, 1991). This is very different from the experience of asylum-seeking and refugee subjects - a context that informs negative perceptions of the term, ubiquitous in political and cultural theory of migration (e.g. see Berger and Kellner, 1993; Bhabha, 1994). It is also a perspective that may question (always in context) critiques of liquid modernity as the root of human alienation (Bauman, 2000). Not only do I consider the Joker's literary texts and real social contexts as instances of societal chaos/destruction, which prompt self-reflexive growth, but see in the socio-philosophical core of this contradiction: a node. This node, which will reappear in other examples of artistic production as travel genres in later chapters, binds many networks of significatory production and consumption of perspective on the status of social and cultural reality. My intention is to travel involved readers through time and space, across millennia and different 'world civilisations', so that I excavate foundational commonalities and differences in the ways reality is constructed and performed in particular styles of mobility we know as 'travel', 'tourism' and 'artmaking'.

'Cosmopolitanism' commenced its life as a project of participation in a 'commons' exceeding the boundaries of communal specificity and aspiring to embrace the world as a shared sphere. For some scholars, this aspiration clashes with the project's rooting in Western and European cultures promoting 
manhood, whiteness, able-body-ness and individuality as universal values (Benhabib, 2002, 2004, 2008; Bhambra, 2016; Nussbaum, 2001; Werbner, 2008). The Western elitist aspects of cosmopolitanism challenge the concept's commitment to inclusivity and borderless solidarity (Rovisco, 2019). For others, cosmopolitanism encloses the possibility to critically evaluate alleged universals, thus building cultural bridges that world travellers cross to meet different perspectival standpoints (Beck, 2006; Clifford, 1992, 1997, 2013; Hannerz, 1990, 1996; Nederveen Pieterse, 2004, 2006b). For yet others, we must heed how liberal communitarian arguments about multicultural ideals produce weaker versions of cosmopolitanism, because they emphasise universalist rights that are anything but equitably distributed or truly universal (Delanty, 2009b, pp.55-56) - a note I take seriously. My own starting point is that world travels of the cosmopolitan type, which can be enacted in the mind, on foot or in endless combinations of these modes of mobility, always generate friction. The concept's twin emergence in philosophy and thermodynamics has facilitated the development of scholarly arguments across different disciplinary (social science and humanities) contexts, in which 'friction' operates as a metaphor. Friction is a magical term, which bridges realms of reality, fantasy and imagination to generate alternative ways of looking at the mundane and the common.

The shift from mechanical to social and political 'facts' is, in itself, a study on and of perspective. For example, Tim Cresswell (2014, pp.107-115) draws on Prussian military theorist, Carl Philipp Gottfied von Clausewitz, to define friction in contexts of war as a series of serendipitous contacts that produce world-defining events. Closer to the cultural cosmopolitan problématique, Anna Tsing (2005) emphasises how friction challenges the universality of universals as 'forms of truth' that can only materialise in the local and the particular (Tsing, 2005, pp.4-6). She sees in this materialisation a form of translation: as a 'grip of encounter' that enables global connectivity, friction, she concludes, reveals the 'unstable, and creative qualities of interconnection across [forms of] difference' (Tsing, 2005, p.4). In fact, her suggestion that we adopt a geo-topographic perspective on friction recalls postcolonial literary theorist, Alejo Carpentier's commentary on the nature of 'marvellous realism'. Carpentier saw in the corresponding Latin American literary trend 'an amplification of perceived reality required by and inherent in Latin American nature and culture' (Huntington and Parkinson Zamora, 1995, p.75). This analysis of the fantastic genre focuses on its dwelling in the 'natural and human realities of time and place', which produces the 'marvellous mixtures that exist by virtue of Latin America's varied history, geography, demography, and politics' (ibid.). Carpentier's cultural-political ontology also connects to Cresswell's thesis, who is more interested in the production of events of planetary significance. Carpentier stresses that the Latin American variation of marvellous realism is 
supposed to differ from European 'magical realism', which emphasises the artistic observer's vision, and thus is clearly epistemological (Farris, 2004).

The present study reconsiders this dichotomy between ontology and epistemology through the ways cosmopolitan friction produces knowledge based on experience, thus facilitating becomings (Tzanelli, 2020a). I return to the European dimension of magical realism below, when I further clarify my methodological framework. All these scholarly dialogues unveil the complexity of actually performing cosmopolitanisms: those that articulate its spirit and law through one's individual existence without even realising or expressing the wish to do so (Beck, 2006, p.19). When we add the conundrum of unconscious performance to the cosmopolitan equation, which clashes with the conscious stylistic projection of cosmopolitan irony, and both to the fact that the cosmopolitan imagination suffers from a difficulty to capture pluriversality, it becomes more evident why I introduce the idea of friction.

For this reason, I renounce cosmopolitan theory's focus on universals and turn to a particular cultural adaptation of development theorist, Arturo Escobar's (2018) notion of the 'pluriverse', to discuss the challenges postulated by the co-existence of actually existing differences. My 'pluriverse' refers to the co-existence of different universes, realms of meaning or lifeworlds, to invoke the structured phenomenologies of Berger and Luckmann (1996), Habermas (1989c) and Mannheim ([1936] 1968), at the moment these come into geographical and symbolic-experiential contact, without necessarily forming a uniform nucleus. For tourism studies scholars, such as Hollinshead (2009) and Hollinshead and Suleman (2018), who fashion similar subject-specific debates, 'pluriverses' would feature as situated enunciations of difference in locales fortuitously or forcefully ushered to tourismification. Tourism theorist Jamal (2019, pp.164-169) nicely accommodates Escobar's call to acknowledge alternative perspectives of being and belonging as non-instrumental, relational ontologies governing life in tourist destinations - something not always respected by the tourist developer. Pluriverses are frictional contact zones caught in the grip of tourist globalisation, mostly managed by national power, tourism experts acting on behalf of capitalist networks or, less frequently by indigenous populations. To speak of relational ontologies, as Escobar (2016, 2018), posthuman ethicist Braidotti (2013) and STS scholar Karen Barad $(2007,2010)$ all have, is to commit yourself to a cosmopolitan worldview that always subordinates economic objectives to the criteria of ecology, human dignity and social justice (Escobar, 2016, p.26).

Notably, this book's cosmopolitan story of friction does not commence with the creative activities of tourism experts, but those of cosmopolitan artists. I will be delving into the articulation of entirely fictional dystopian contexts by Joker's transnational community of audio-visual technicians, filmmakers and writers, which allegorise the current breakdown of social bonds in American 
pluriverses before moving on to the reality planes of unplanned tourismification. As Rovisco (2013) has already noted in her work on cinema, some filmmakers' work voices structures of feeling (i.e. care, compassion and empathy) that enable the audiences' affective and intellectual engagements with 'others', whose access to cultural dialogue is limited. It is important to note that these cosmopolitan artists did not mobilise their transnational imaginaries in artmaking so as to generate tourism. The spontaneous eruption of film-induced pilgrimages around a movie featuring an anti-hero and condemning American social fragmentation, lack of solidarity, love and care, is an event built on a cultural translation (of a fictional personal story of descent to madness and crime into tourism performance) of a realist translation (of what is called an 'artist critique' (Chiapello, 2004) of the failures of modern life). Despite its intentionally grim fictional-realist surface, the story is filmed as a perspective on the world, only we never know when this perspective is the anti-hero's making, or that of someone watching the social realities in which he finds himself. As a critique of welfare retrenchment that deprives a man wanting to make others laugh of his medication and sanity, the film makes viewers work hard to figure out whether at times they are transported to a magical world (in which there is love even for Arthur) or just a dilapidated Bronx apartment in which he hallucinates about having a romantic encounter with his neighbour.

This palimpsestic making of reality is the 'stuff' of urban mobilities, which are not always backed by considerate design that meets the needs and capabilities of different communities (Jensen, 2013, 2014; Jensen et al. 2016; Büscher, 2019). Urban palimpsests store fragments of collective memories and the violence of amnesias, Huyssen (2003) argues. Following philosopher Peter Sloterdijk, he invites critical engagement with the past so that we counteract practices of 'uncreative forgetting' or 'enlightened false consciousness' (ibid., p.10), which either neutralise traumas to enable their anodyne consumption, or lead to uncontrolled eruptions of memory that kill people. Tracing the 'afterimages' of collective traumas - the outlines or shadows of artefacts, ideas and monuments vandalised and destroyed (ibid., p.163) in the name of a cause - is the job of the critical artist, the scholar and lay citizen, who refuse to either forget or let the past hinder the creation of viable futures. The outcome of this remembering, which actively seeks to interpret, rather than reproduce past events, aims to introduce the community to different angles of the same event, to teach that different discourses enunciate and thus create it anew. Again, such acts of reconstitution, which are also translations of events, are travels of the mind that bring into focus the ability of artists to mobilise irony in socially productive ways.

I disagree with Rancière's (2009, p.31) suggestion that 'frames of visibility' always 'put things or practices together under the same meaning'. The ways communities make shared pasts visible and intelligible to themselves and 
others can find radical modification when a sense of irony is introduced in these pasts' perspectival release. In cosmopolitan filmmaking this enterprise turns commoditised narratives (the films themselves) into ways of reconfiguring 'the visibility of the common' (ibid., p.48), thus throwing certainties of commonality back into dispute. Because filmmakers are world travellers, their work filters the 'visible common' (ibid.) through a multiplicity of conceptual, ideational and experiential itineraries; as a result, the 'commons' with which they associate themselves acquire the quality of a kaleidoscope. The same creative act of making things 'visible' or 'invisible' to the world will be observed in non-Western contexts of 'translation', such as the Japanese, which will form another context in which attitudes toward cosmopolitan irony becomes productive of worlds (of travel and tourism).

Evidently then, when I speak of 'translation' I do not refer to textual interpretations of culture but an 'interdisciplinary field, the focus of which is the study of cultural interaction' (Bielsa Mialet, 2010, p.156; Bassnett and Lefevere, 1998, p.6) in globalised contexts (Cronin, 2000, 2003, 2006, 2013). Likewise, I do not use the idea of 'travel' or 'tourism' as a medium of irony that supports forgetting, but a method enabling the hermeneutic organisation of our fragmented pasts and presents, to rescue critical afterimages from the rubble of modernity. On this, Latour's reflections on translation are critical, because they introduce non-human actants in social interactions, such as forms of media - a crucial element in this study's analysis. He cautions us that the myth of the medium as a 'neutral tool' subjected to complete human control and that of the human being's 'autonomous destiny', which is not entwined with the tool's potentiality to direct action, are symmetrical. It is more apposite to treat both as an interactive complex operating through 'translation'. By translation Latour (1994, p.32) refers to 'displacement, rift, invention, mediation, the creation of a link that did not exist before and that to some degree modifies [the] two elements or agents'. Media act as both tools and symbols in social interaction, because they introduce uneven dialectics in communication - what Silverstone (2007, pp.108-109) examines as 'mediation'.

I do not rush to consider filmmakers or local interlocutors as uncritical ironists or resentful hosts before careful investigation of the social context in which they act. Cosmopolitanism as a form of translation is a critical pedagogical project, which involves reciprocal cultural learning (Delanty, 2014, p.384). As an academic project, the study of cosmopolitan translatability calls for a more grounded approach, seeking to operationalise theory through empirical instances (Bielsa, 2014; Lamont and Askartova, 2002; Nowicka and Rovisco, 2009; Skrbis and Woodward, 2013). Such instances endow the present study with a core problématique: to both acknowledge specificity and the multiplicity of viewpoints (Skey, 2012, p.477; Stevenson, 2014, p.183). The collection of different perspectives is a hard job, which I manage as part of a team made 
up of people that I never met in person: mostly journalists. Methodologically, this book is indebted to the work of journalistic journeys into the pluriverses I explore and their storytelling of relational ontologies between hosts and guests, and artists and their audiences. Journalistic stories helped me reconstruct such cosmopolitan palimpsests in a scholarly style that differs in terms of approach from the original stories (on the journalistic field and cultural translation see Bielsa 2008; Bielsa and Bassnett, 2009). At the same time, the journalists' tendency to record opinions and ideas verbatim allows me to examine the perspectives of other important para-informants, including artists involved in the making of the Joker and tourists in the Bronx, where some significant scenes were filmed and generated tourism. 'Translation' and 'metaphor' suggest multiple semantic movements across time and space, of ontological significance in domains of cosmopolitan friction.

For these reasons, my methodological portfolio actualises cosmopolitan epistemologies in less orthodox ways. My methodological starting point on 'cosmopolitan friction' is the material (geographical, context-bound) and phenomenal effects of cosmopolitan encounters. To slowly return to the European artistic roots of magical realism, I note that real contact zones of cultural activity and encounter between pluriverses and the outside (including tourists, journalists and filmmakers) produce atmospheres of luminosity. 'Luminosity' is an atmospheric concept that refers both to the visible-sensible outcome of friction (we see 'areas' of light in the natural environment) and metaphorical illumination (of under-theorised areas begging for analysis and clarification in a critical style resembling Walter Benjamin's ([1936] 1968; [1968] 1992) hermeneutic project). Atmospheres of luminosity are akin to particular viewpoints, angles of reference in a scholar's cosmopolitan analysis. Thus, whereas my ontological and experiential portfolio draws on postcolonial marvellous realism, my methodology follows the epistemic nature of filmmaking that speaks the language of European magical realism: genuineness via technology.

To adopt such a geolocative perspective is not to endorse regional analysis or methodological nationalism: my focus on instances of cinematic representation, reception and tourismification points to a critique of such methodological simplification in Beck's (2016) critical-analytical style. We must think of the ways persistent and continuous friction produces sparkles and even fire, thus bringing attention to 'hotspots' or activity epicentres. It is this attention to spot and angle that I wish to exploit in this study as a methodology of perspective. Aware of the complex intertwining of aesthetics and ethics in the cosmopolitan imaginations (a term I pluralise, contra Delanty [2009b]), I turn my attention to a particular translation of two Eastern epistemological techniques into globalised technological innovation: the bokeh and the selfie. Both will form gateways into processes of cosmopolitan irony across Western and Eastern 
cultures that thrives on mobilities, such as different forms of (old and new) technology, travel, and variations of pilgrimage.

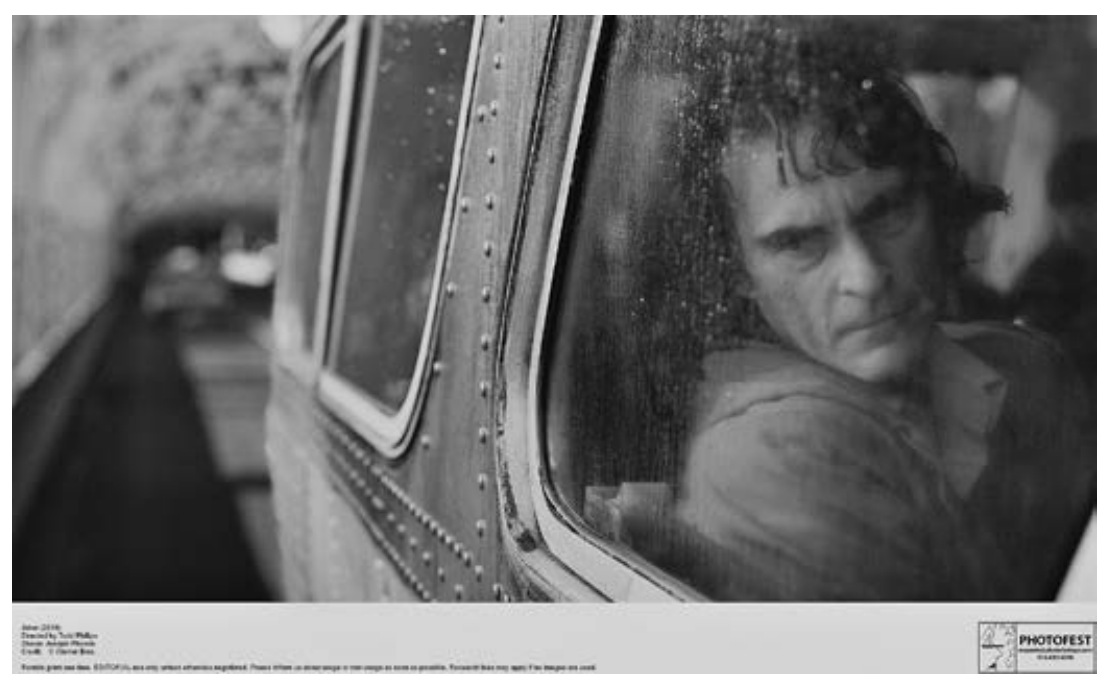

Note: The outside forms a bokeh to communicate his disturbed psychology.

Source: Warner Bros/Photofest, 2020.

Image 1.1 Fast moving images of Gotham are blurred in Arthur Fleck's mind

Bokeh is the aesthetic quality produced by blurring parts of a photographic image so that particular regions are sharply focused. The term originates in the Japanese word boke, which refers to 'blur' or 'haze' and is derived from the verb bokeru. The verb presents a variety of meanings, ranging from being blurry or out of focus, to behaving childishly, being senile, befuddled or even performing naivety/stupidity, as well as becoming engrossed in a detail (Online Japanese Dictionary and Study Portal, undated). Boke's transposition into Western technology originates in the use in 1997 of the term corrupted as 'bokeh' in the magazine Photo Techniques. By that time, both spellings had been in use for about a year by a self-taught student of Japanese who wanted to read photo magazines in their native language (Johnston, 4 April 2004). The depth and quality of bokeh are determined by the make and quality of the lens: for example, 'good' bokehs corresponding to sharpening foreground images, such as portraits, necessitate good long tele-photo or macro lenses to produce a shallow depth of the field so that the subject 'stands out' against the blurred background. The arrest of Arthur as the killer of his TV show host, Murray 
Franklin, towards the end of the film, provides such a good bokeh moment: watching from the window of the police car as riots break out across the city produces a sharp focus of his demented character against blurred city lights and riot noise.

Hence, its technological function aside, bokeh is an atmospheric concept. Common-sensical understandings of 'atmospheres' as 'ambience' or 'moods' induced by our perception of our environmental surroundings, are important for the concept's definition. Atmospheres orientate humans in the environment, but this orientation is based on what they perceive of as their real environment. Atmosphere's philosophical rendition in Germanophone hermeneutic phenomenology as 'Stimmung' (literally the uncanny), suggests that its qualities are based on an environmental connectivity between the human subject and the object on which their perception focuses (Heidegger, 1967; Bollnow, 2011). Thus, atmospheres are constellations of people and things, or 'ecstasies of the thing': the way the perceived thing (and corresponding unfolding event) qualitatively and sensuously stands out from itself (Böhme, 1993, p.121). Light and illumination are specific atmospheric manifestations that have found ample use in the cosmetic organisation of urban environments (Edensor, 2012).

However, as explained before, this study facilitates a metaphorical elaboration on the cosmopolitan complexities of friction through philosophies of the moving image, which display both potentialities and limitations. Thus, I have less interest in following Edensor's study of atmosphere as such and more on using his placement of atmospheric installations as epistemological tools. Simply put, my makeshift bokeh cosmopolitan travels will hopefully facilitate spatio-temporally focused sociological illuminations of frictional events as these events are perceived by those participating in them. That I am added in these environments as someone perceiving others' perceptions is not a separate problématique but a phenomenon constitutive of my sociology of perspective. I will return to this in Chapters 3 and 4, where I will further unpack the aforementioned magical realist split between European artistic epistemology and non-European postcolonial ontology.

The elaboration is of methodological significance, if we follow Bauman's hermeneutic contribution to the social sciences. Bauman (1978, p.218) argues that 'by spotting the general in the particular, by enlarging both the alien and one's own experience so as to construct a larger system in which each "makes sense" to the other' are essential components of hermeneutics. I add that this approach from the standpoint of the particular, the bokeh, does not just make them comprehensible ('makes sense'), but also sensible: aesthetically and therefore culturally translatable. Where Bauman stresses cerebral comprehension, I focus on the contribution of its performative and embodied dimensions in this cerebral enterprise. This stresses how our being is trained to perceive 
the world, before we proceed to change this habitual environment and rituals to enable cross-cultural comprehension. Indeed, cosmopolitan friction (the moment of contact with the other) is the 'event' or momentum captured in a 'good bokeh' at a particular moment in time. Capturing it in the moment so that it is examined carefully at a slower pace, signals the passage from immediate multi-sensory encounter to reflexive apprehension (its social-scientific elaboration). In fact, for someone wishing to approach perspective with some critical sensitivity to cultural and social difference that does not concede to unlimited altruism, 'good' and 'bad' bokeh techniques may stand in a critical reversal - an observation applying to the destructive revolution of the disenfranchised populations of Gotham City, as this is metaphorised in Arthur's demented bokeh. Rather than resorting to an a-political aesthetic analysis, my approach to cosmopolitan friction hinges on the politics-with-aesthetics approach that we find both in Jacques Rancière's $(2009,2011)$ work and in Felix Guattari's (2014) 'three ecologies' thesis.

Guattari's analysis is particularly germane for inspecting angles of cosmopolitan friction. He begins by positing the presence and interaction of three distinctive 'ecological registers' involving the environment, social relations and human subjectivity (ibid. p.18). However, his conception of the environment refers not specifically to natural ecosystems, but the ways the mental plane interacts with subjectivity. This refers to people's attitudinal dispositions, sensibility and minds, which Guattari believes to have been penetrated by media homogenisation processes to produce a dangerous singularity of perspective (see also Guattari and Negri, 1990, p.53). A similar analysis was recently fashioned as Bauman's methodological stance against fundamentalism. In his assessment of the thinker's critique of public use of social media, Davis (2020, p.28) reminds us of Bauman's warning that such habitual technological use isolates people, because it allows them to just reproduce their own perspective. However, this disregards the cosmopolitan potential of technology and its facilitation of transnational dialogues. More helpfully, Bauman (and Davis) suggest that 'real dialogue isn't about talking to people who believe the same things as you' (Bauman and De Querol, 2016). Their second useful observation is that often fundamentalism does not support 'a primordial surfeit of meaning' but is the outcome of a deficit in meaning (Davis, 2020, p.30). I see in the latter one of the most discussed 'conditions of modernity' (Bauman, 1991), so any elaboration on it demands context to avoid abstraction.

Although Guattari's ecological model would suggest the interlacing of cosmologically bound artmaking with the local or native language, and the translation of both as homeliness, at-homeness, or as a form of hospitality (i.e. 'this artwork belongs'), its abstract nature does not invest in cultural cosmopolitan specificity (Tzanelli, 2020a, p.179). Guattari (2014, p.47) is more interested in stressing how, despite their common origin in the ethico-aesthetic 
discipline, the three ecologies should be distinguished from it as practices. Where Guattari suggests that we resist capitalist domination by revolution, I caution that 'specificity' and its resurgent potentialities - what in Chapter 4 I investigate as a 'narrowing of vision' - can also produce the opposite of cosmopolitan openness. In the next two chapters it becomes more obvious how in the history of national and cosmopolitan artistic representations of the rebel and rebellion - the common folk ironist - the Joker's bokeh can be very bad indeed, as it produces versions of methodological nationalism, nativism and fundamentalism. By the time we have reached Chapter 4, we will be in a position to understand how real social inequalities generate good analytical bokehs but very bad ecologies of perspective for sustainable futures.

To examine cosmopolitan pluriversals, one needs to adopt a slower pace that is contextual and relational at the same time; favours phenomenological analysis (e.g. Vannini, 2013); and most importantly, thinks of atmospheric phenomena, such a 'friction' as processes. In both Cresswell's (2014) and Tsing's (2005) work, process is subsumed by or ignored in favour of materiality and metaphorisation respectively. The omission is strange, given that the new mobilities paradigm and the discipline of anthropology share in the realist belief of what Adey (2010, p.149) posits as everyday mobilities' 'thinking-feeling' articulations. Although I pay less attention to the automobile revolution of modernity/modernities as such (e.g. Featherstone, 2004; Urry, 2004; Sheller, 2014), its implication in the social machination of the human body that Deleuze and Guattari (1983) discuss is indisputable. If friction in cosmopolitan encounters grants this study's analysis with atmospheric process, the real 'event-technique' of cosmopolitan performance (by artists, tourists and locals) is the bokeh nature of the selfie. Practices of 'zooming in' and 'closing up' foreclose or enable potential connectivities based on ironic critique, by delineating spaces and culture as 'our own', by making, erecting or demolishing borders (Rumford, 2014).

This brings me to a brief introduction of the selfie and its relationship to the bokeh. Selfie tourism features as a cosmopolitan frictional zone in this study, due to the spontaneous generation of tourism from the Joker in a poor American neighbourhood (on tourism and the border see Timothy, 2000, 2001). Local grievances about the selfie tourists' insensitivity are examined in Chapter 4 as instances of damaged hospitality, after a scrutiny of what the selfie really is and where it comes from in Chapter 3. Selfie techniques and popular cultures are not necessarily identical in their intentions and motivations: as I explain in Chapter 3, the contemporary selfie as a technique involving pointing the camera at oneself, can be an ironic statement on individuality, or a way to connect to the world and laugh at oneself's flaws. Contrariwise, the technique of individual and collective self-centrism and narcissism is an attack of both individual and collective growth and wellbeing. 
There is a structural likeness between bokeh and selfie techniques relating to the Japanese origins of both and their subsequent Western technological translation into expressions of individualism, subjectivity and material-phenomenological border-making. Especially bokeh's original linguistic connection to performative innocence or knowing silliness in the boke marks a cultural border between propriety, transgression and belonging. In Western techniques of selfie-taking, this border is moved closer to practices of self-care even at the expense of caring for others - a change also reimported into modern Japanese culture in the era of globalisation. Such border-making feeds back into concerns regarding cultural translatability. Note for example, that, although the translatability of cultures features as a conditional form of cosmopolitanism, the process of translation itself may be informed by invisible, discursive violence pertaining to the domination of one cultural form over the other (Asad, 1986; Herzfeld, 2002; Tzanelli, 2015).

In the following chapter I return to this journey's starting point in the study: the creation of the Joker in the old garments of Arthur Fleck, the poor clown with no future or sanity to navigate the world. I discuss the creative vision of its makers and their intention to produce a critique of Western American cultures of thoughtlessness, through the withdrawal of hospitality in the form of welfare. I also explore the reasons and cost of choosing a particular style of narrating these artistically. This will help me regress in Chapter 2 to the origins of the concepts and characters with which the Joker's creators had to engage in contemporary (comics) and historical (national literature and painting) popular cultures depicting transgression, rebellion and revolution. This will move us away from the film and into the recesses of cosmopolitan friction, as this is contextually enacted across different times through interplays of social status, power and identity.

\section{RETHINKING PILGRIMAGE}

The promise to travel readers through millennia of human creativity generates more methodological and practical questions: how is such travel performed? Does it involve any continuity or association with organised tourism? Who can enact it? The questions multiply, if I do not clarify that I will be working along two axes of movement that have both multi-temporal and multi-spatial qualities on the one hand (horizontal axes), and cognitive, spiritual and affective qualities on the other (vertical axes). These axes evolve on a three-dimensional scale, by moving upwards or downwards and/or warping inwards, until the travel transforms into a tourist journey focusing on a particular destination, spot or neighbourhood, as is the case with the Joker. As the schematic organisation of this axial development attests, 'travel' begins as a purely cognitive activity involving interpretations of artistic creativity and proceeds all the way 
up to transforming into an embodied popular cultural pilgrimage in a particular location, or down, to transform into religious worshipping. However, between the first and the last transformation, one must account for the interpretative gaps that the researcher has to fill, as different spatio-temporal plateaus move between and across the two axes. Embodied tourism aside, such movements can be virtual - that is, emotional and cognitive - but also digital - if we account for the changes new systems of mobility introduced in our lives in the last two centuries (see Figure 1.1).

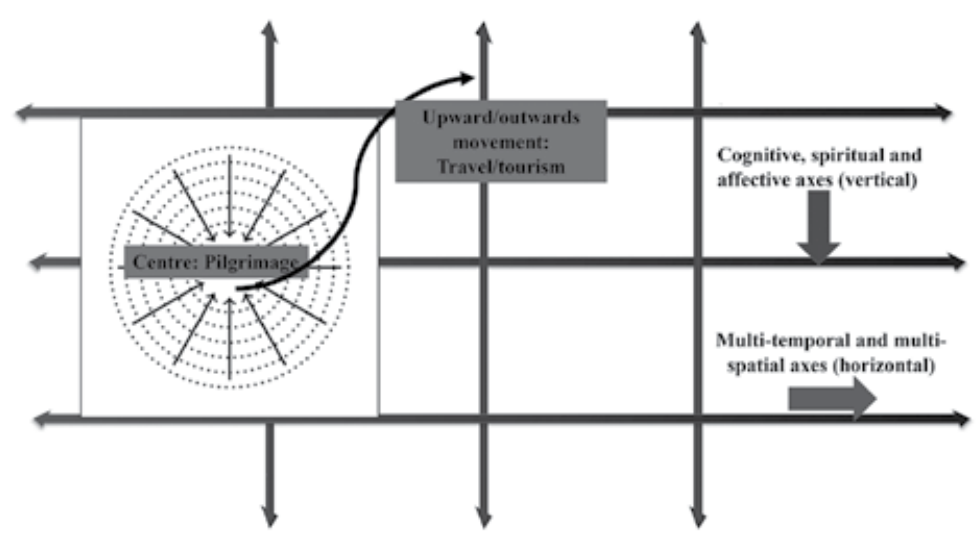

Note: There is purposive movement of three-dimensional quality in image-based pilgrimage that applies across the explored examples of cosmopolitan mobility in this study (protest, selfie tourism, film-tourism, digital tourism and artistic calligraphic travel).

Source: Rodanthi Tzanelli, drawn in 2020.

\section{Figure 1.1 Pilgrimage and Axes Mundi}

The recognition that new media, especially those embedded online, maintain a link to travel and organised tourism, has featured in several publications dating back to the very start of the twenty-first century (Prideaux, 2002). However, such early analyses focused mainly on the materialities of tourism, including the internet's infrastructural facilitation of conventional tourism, not what Germann Molz (2012) later flagged as a question of 'networked sociality' that acts as a form of 'novel interactive travel' (Germann Molz, 2012, pp.2-4). Germann Molz's reflections included little elaboration on the phenomenologies of such virtual connectivity beyond an analysis of travel affordances and the production of alternative socialities. This conspicuous gap invites reflection on what it means to use the internet to travel, not just in terms of community-making, as Molz's excellent analysis attests, but phenomenologically, in terms of the quality of this movement (see also Hollinshead 
and Kuon, 2013 on tourism studies 'fluid acumen'). Rosie Braidotti's (1994) configuration of the 'nomad' as an analytical tool that helps us to understand migratory-travel practices is a useful starting point. Much like Bauman's (1996b) configuration of the tourist and the vagabond, Braidotti stresses that mobility is not limited to physical movement, but accommodates multiple levels of experience that allow us to blur boundaries between different mobilities and work towards ways of knowing about alternative types of movement. When geography is removed from the picture, we can contemplate an epistemology of movement (Braidotti, 1994, p.23) that may allow us to reintroduce geographical specificity in comparative studies of place and culture.

Several decades before Molz's analysis, Graburn (1978) called for a 'cross-cultural aesthetic' approach to tourism as a sacred journey, promising a break from ordinary life in 'a spiritual quest for the ultimate truth' (p.24). Such analyses of tourism as a psychic 'meta-movement' propelling individual and collective changes (Coleman and Eade, 2004), encouraged further study of the intersection between tourism and pilgrimage. Anthropological classics of an obvious Eurocentric flair, such as Turner and Turner's (1978) Image and pilgrimage in Christian culture, further prompted scholars to consider pilgrimages as both religious and secular, tourismified forms of mobility. These analyses were based on notions of the social world as a Heideggerian picture-postcard, ready to be experienced, apprehended, and consumed. Yet, continuums between experience, apprehension and consumption are not to be taken for granted. This is also the case with pilgrimage as an image-based ritual and a worship of deity icons. Studies of religious pilgrimage in Islamic contexts stress Islam's aniconic or non-representational nature (Tzanelli, 2011), whereas contemporary popular pilgrimages (e.g. film tourism, music tourism, forms of dark tourism) of iconic nature prioritise the "pilgrims", ritualistic emotional investment in the practice itself (Couldry, 2003; Beeton, 2006; Tzanelli, 2013). If anything, secular and religious pilgrimages are morphologically connected: they both look to the subject's break from ordinary (profane) time; demand personal investment in an idea that shapes the subject's perception of the world; organise this perception with the help of ritualistic repetition of worshipping practices; and promise some sort of psycho-cultural transformation of one's inner self from afar.

The bokeh/boke and selfie-taking will structure the journey through millennia of world civilisational development that I promise to my readers. At first, the generation of any methodological and empirical links between popular cultural pilgrimage in the Bronx and a centuries-long development of the boke from Eastern and particularly Japanese calligraphic art to selfie tourism may sound absurd. As will become evident in the next few chapters, my analysis is equipped to make such connections epistemologically and ontologically useful because of such journeys' constructions as a global cultural circula- 
tion with its own political economy. Du Gay et al. (2013 pp.4-8) spoke of the 'circuit of culture' to analyse interplays between media representations, meaning-making, identity formation, production and consumption, as well as regulation, whereas Lee and LiPuma (2002), Cronin (2004) and Valaskivi and Sumiala (2014) discussed circulation as a cultural process with its own dynamics and constraints in commercial contexts. My assertion that we can enact a coherent journey through different cultures and in different spatio-temporal frames highlights both the journeys' global circulatory quality in modernity and their complex connection of premodern and late modern circuits of belief (Colebrook, 2006).

To put this leap of faith in diachronic mobility in context, I wish to develop a broader account of how social worlds are created and maintained through cross-cultural mobilities, such as those produced in boke/bokeh and selfie cultures. To achieve this, I heed Couldry's (2012) advice that, especially to study cultural politics in media contexts, we must learn to treat linear perceptions of social reality with suspicion. To accept the free flow and circulation of ideas across different cultural contents and times as a methodology, we need to forgo perspectives reliant on linearity and immateriality and learn to use particular traces such journeys leave on social domains as our guides or signposts (Latour, 2005, p.79). If we accept this course of action, we become involved in multi-dimensional forms of pilgrimage: not only do we have to enact cognitive and emotional journeys into different worlds, we turn cultural circuits within and points of connection between these worlds into the object of our study.

That I focus on transformations of pilgrimage into a secularised, popular culture in virtual environments, should not mislead readers to think that I separate economics from the politics of cultural circulation. Coleman and Eade (2018) note that historically, the voluntarism and egalitarianism of pilgrimage provided antecedents for contractual relationships, thus subsequently playing a significant role in the formations of capitalist landscapes in modernity. First of all, much like Cresswell's and Tsing's theses on friction, this type of pilgrimage invites macro-sociological analysis. It involves more than a focus on collective and individual appropriation of cinematic and literary stories, as well as accompanying artefacts, architectural structures and geographically demarcated sites and landscapes. It is more associated with the organisation of meta-movement within a virtual system of services that at least in neoliberal contexts of labour mobility interweaves capitalism with religion and both into the nation-state's economic, political and legal structures of place-making and naming (Coleman, 2014, p.283).

By the same token, we cannot think of the 'pilgrim' as a phenomenological traveller only. The pilgrim is a subject that transcends old secular vs. post-secular epistemic frames, because (s)he enters domains of economic performance and environments constantly structured and restructured to 
appeal to new markets (Gauthier et al., 2013). On the one hand, this creates ever-expansive realities for the pilgrim-subject as an ideal type: not only does it open new possibilities for performing travel as an imaginative/imagined form of movement, it pluralises the ways such travels are relayed to others. On the other, ideal pilgrims, including cinematic tourists, can be understood better when they are associated with particular ideological formations - otherwise put, if we consider their mobility habits and lifestyles first outside the 'shrines' that they visit (Singh, 2012). The observation is significant, not just for the tourist mobilities induced by the Joker in the Bronx, but also the development of premodern Japanese boke/selfie cultures into an assemblage of commercialised pilgrimages in modernity in Eastern and Western urban sites (only this demotes the film and its tourism mobilities into an example, rather than the real focus of this study). I discuss these transformations across Chapters 3 and 4, so that I examine closely the emergence of cosmopolitan networks of mobilities blending tourism, pilgrimage, labour migration and technology from the 1990s. These networks are not actually 'spoiled' because they are commercialised: for better or worse, the ethos of commercialism has been part of their genesis and development. Indeed, the idea of a commercial system (Reader, 2014) or multi-site (Tzanelli, 2018) have always been part and parcel of studies into Japanese pilgrimage. It is also not injudicious to argue that structurally, this phenomenon is manifest across different places that hosted secular, religious and post-secular pilgrimages, thus partaking in globalising processes (Cresswell, 2015, pp.83-84). Thus, my approach cannot be limited to established approaches on 'simulation' in consumerist ideological contexts, but also involves pluralising representations of existing landscapes, heritages and cultures of actual sites and increasingly tourismified destinations. Much like markets, which act as heterogenous assemblages of human and non-human actors and institutions (Osella and Rudnyckyi, 2017), ideas of place are malleable (Cresswell, 2015, pp.109-110) - or should be to some extent, if we do not want to adhere to fundamentalisms that different interest groups use to fix cultural memory. Hence, we must treat the classical political economic approach propagated by Baudrillard (1994) as only one of many prospective epistemological frames in this study's digital journeys.

There will be likely objections from tourism scholars and practitioners to a scholarly approach which proposes virtual peregrination or 'websurfing' of cultures and landscapes as a form of touristic pilgrimage. Such objections tend to ignore some factual occurrences: first, that a reading of popular cultural pilgrimages of the Lord of the Rings or Pokémon Go type as generic 'consumerist packages' tends to reproduce the old normative divide between serious travel for pedagogical purposes and 'pop' tourism for brain-wasted consumers (McCabe, 2005). Second, clinical separations between 'virtual' and 'embodied' pilgrimage are discriminatory in the most real sense, as they confine the 
true, 'authentic' experience of mobility to those who can move physically. Third, websurfing is now the first phenomenological window that tourism systems open to other world cultures, thus producing a prospectively embodied (tourist) clientele. Finally, it is noted that, when virtual pilgrimage is viewed as just an early 'phase' of mobility, leading to more 'accomplished' experiences of 'being there' in the flesh, it never acquires the status of an independent case for study epistemologically and methodologically. Each of these observations reintroduces a discussion on interconnections between reality (what we apprehend, consume, visit and relay to peers), subjectivity (how we produce our own subjective status as 'tourists' and 'pilgrims'), and identity (how both tourists and popular pilgrimage destinations come to be named and claimed, as well as by whom). They prompt an examination of aesthetic engagement with the world 'out there', as well as what constitutes the world within our mind. This has been expressed by philosophers as the divide between 'externalism' and 'internalism'.

It is worth reaching back to Graburn's early work. Virtual peregrination typically exhibits a particular aesthetic texture, because it can be both episodic (we visit places online whenever we have time), intimate/personal (we can do this completely alone) and labour-intensive (we do this in early or late hours, or even during work times, but still with immense emotional investment). It is aesthetic because it enables (a) sensory (think of aesthesis in terms of senses) (b) formations of what is beautiful (aesthetics as appreciation of beauty, harmony and coherence) that (c) lead to apprehensions of the built and natural environment around us (Tzanelli, 2018). If these three aesthetic dimensions sound suspiciously European/Kantian, a fourth may be added: the subconscious hybridisation of sensory inputs and outputs that feed into aesthetic appreciation, which differ from culture to culture. In any case, the permeation of touristic-like pilgrimage as a practice by images and texts (we visit places through their online photographic, auditory and textual descriptions), shapes our engagement with the represented or simulated social and cultural worlds.

Methodologically, we can think of virtual pilgrimage in two analytical stages: in the first stage, we may explore the extent to which the material immediacy of the world exists independently from the websurfer's comprehension during their virtual journeys; in the second stage, we may consider pilgrimage online as 'irreal', in that it encourages the human mind to produce several world versions, each of them valid in its own right, and thus methodologically productive. Although this proliferation of worlds crosses paths with a specific version of reality produced by cyber-experts in tourismified pilgrimage business, it is ultimately irreducible to their dominant, let us say, imposed 'reality' (May, 2008).

The irrealism that I propose re-examines understandings of 'worldmaking' as a force that shapes tourism around the world. Hollinshead defined this as 
"the creative - and often "false" or "faux" imaginative processes and projective promotional activities - which management agencies and other mediating bodies engage in to purposely (or otherwise unconsciously) privilege particular dominant/favoured representations of people/places/pasts' (Hollinshead et.al., 2009, pp.430-431). Borrowing from Goodman's (1978) predicament that we are neither able to encapsulate the 'world' as such, nor know that it exists as a uniform or fragmented totality, or as plural totalities, Hollinshead develops a novel take on tourismification. His 'worldmaking' is notably more 'closed' than Goodman's, because it stresses that tourism experts select a singular world version. As business agents, they stabilise cultural reality in tourist destinations. Theoretically, outside tourism studies, Hollinshead's worldmaking is not based on Goodman, but on Hilary Putnam's (1996) and Nikolas Rose's (1999) takes on Goodman. Simply put, what is ultimately 'real' in tourism contexts, as the revered (by popular cultural pilgrims) landscape, artefact or narrative, is what some 'finished science' will eventually say is real and thus ready for us to experience or consume. Within tourism theory, this resembles Urry's thrice-revised 'tourist gaze', which was originally defined as the gaze of 'experts' that make tourism (see first edition, Urry, 1990).

Hollinshead's work has commonly emphasised the ways in which worlds of tourism are structured by industries and experts. It leans towards the ways through which reality closes in on us from someone's perspective (from the scholar, the professional or the state). This trend informs his more recent collaborative work, which, borrowing from Nünning et al. (2010), explores 'how social scientists themselves conceivably compose the vistas through which they make the very constructs that they deploy to carry out these worldmaking inspections' (Hollinshead and Suleman, 2018, p.209). Such observations strengthen Hollinshead's communication with Putnam or Rose. Their variations of 'irrealism' - the proposition that worlds proliferate all the time and experts step in to tame this process by selecting one version - and the adjacent debate on whether or not one or many versions of the world exist independently from our thinking of them are technical through and through. 'Sorting' the connection between externalist and internalist world-versions informs the reality-making of the technocratic planner and the policymaker. Although blends of tourism, pilgrimage and work do exist, they do not inform the disinterested tourist or pilgrim of leisure, as we know them. Whilst Hollinshead's thesis outlines the 'discursive' power of the tourism business à la Foucault, it is less effective for virtual touring as an individual practice and a collective, popular cultural ritual of the 'pilgrimage' range. We must then revert to Goodman's original suggestion to acknowledge that, as human beings in our digital journeys, we may create and inhabit different worlds. These may or may not cross paths with those of digital tourism and business experts: capital holders, advertisers and web designers. This version of worldmaking is 
closer, though not identical, to what is promoted by tourism scholars working within earlier hermeneutic traditions (see Caton, 2013). A few examples may be helpful.

Studies on 'gamification' as a motivational experience that leads to visiting places are a case in point. I will not endorse discourses of 'incentivisation', which reduce online engagement with landscapes, cultures and customs to a money-making strategy. Playing a computer game, so that we familiarise ourselves with a real (physical) site, certainly follows a 'script' devised by designers. However, the involvement of designers in knowledge-making about place and culture is ontologically conducive in a pluralistic sense. It produces versions of the world(s) that it represents in the minds of game-players, which were not necessarily part of the designers' script. A notable example is the Brazilian Tourist Board's (EMBRATUR) introduction of the 'Brazil Quest' an entertainment game intended to 'educate' prospective (digital-to-terrestrial) tourists in Brazil during the 2014 FIFA World Cup (Corrêa and Kitano, 2015). Such gamifications feed into initiatives pertaining to the 'festivalisation' of the city and straightforward urban tourism, emphasising popular pilgrimages to heritage sites and postmodern entertainment and consumption hubs (cinema complexes, bars, galleries, stadiums, local markets) alike. Such pilgrimages are, in the original sense, peregrinations, urban flâneries that separate the game-player from ordinary time, prompting an investment in a cognitive meta-movement.

The proliferation of digital itineraries connected to cinematic adaptations of 'swords and sorcery' literary genres is another case in point. Whole websites are now devoted to the reproduction of such fantastic worlds in a map-making fashion and with various adventurous plots. Independent subcultural universes emerge and spread from such corporate design of sites (usually linked to the movies' production companies), with their own plots, rituals and connectivities. The Lord of the Rings and now the Hobbit trilogies were pioneers, with ever-expanding international fan groups, which now 'move' online and share in blogs, online diaries and via digital game-making. The Game of Thrones franchise prompted the design of several websites advertising landscapes from different countries that were used in filmmaking, suggesting more online visitations of remote, beautiful places by digital flâneurs.

These initiatives are digitally productive and reproductive of worlds, in which some form of community emerges. Examples include variations of digital pilgrimage connected to The Da Vinci Code, with Louvre tours sitting next to genealogical searches in Scotland and 'new age' cult sites promising the retrieval of pan-human roots from Dan Brown's story. A second is Avatar's connections of real environmental activism in the Amazon, Brazil (one of the movie's inspirations). It involves simulatory journeys into fictional Pandora's natural environments, which have now acquired a global pool of pilgrims. 
The cybersphere of popular pilgrimage is a sphere of several lifeworlds, often co-existing uneasily and at the expense of each other. However, one thing is sure: the design of such digital universes does not merely allow for endless transformations of leading narratives of place and culture in a 'popcultural placemaking loop' fashion (Gyimóthy et.al., 2015, p.18). It also does the unpredictable cultural work of community-building, which shapes real human connectivity 'from afar' and in a peculiar neo-cosmopolitan fashion open to more people around the world with an internet connection (Szerszynski and Urry, 2006). In this respect, several worlds from every online 'popular cultural pilgrimage' by digital pilgrims/flâneurs may emerge independently from those designed by technical experts.

It would be problematic to conclude that digital worldmaking involves only the management of reality in a rational and technocratic sense, with individual digital tourists/pilgrims as the true experiential world travellers and the makers of cyber-pilgrimage as 'armchair technocrats'. Still, in my analysis of popular cultural pilgrimage online, I do not espouse Urry's traditional split between romantic and mass tourists. Nor do I maintain, following Urry and Larsen (2011, pp.201-203), that gazing at real and fictional places or celebrating ideas and artefacts in tourismified contexts, instantiates terrestrially and socially existing practices, divides and identities (e.g. the 'Romantic gaze' is possessed by middle-class tourists). On the contrary, I argue that, when in the cybersphere, we arrive at fortuitous blends of the two types of tourist/pilgrim, with the possibility of arriving at a third: that of a sort of the "popular cultural worldmaker'. The popular cultural worldmaker traverses the world of digital designers while making new worlds, both alone and in unison with other websurfing pilgrims, with whom they can join forces in forming a community. These 'popular cultural worldmakers' can be romantic in their pursuit of personal sublimation through online travels, but also mundane in their fusion of work with virtual mobility. They are prone to hybridise ideas, rituals and practices, because no world narrative remains completely stable, but is always subject to alterations on the move. In this respect, popular cultural worldmakers may be viewed as popular artists of sorts, in constant dialogue with the technocraft of touristified digital business.

This take on 'artistry', which amplifies the violence on reality and on human subjects, is crucial for the book's central thesis. The following chapter explores the first phase of morphing the Joker pilgrimage in Todd Phillips' rendition of this DC Comics anti-hero. To do so, I regress to an irrealist exploration of the hero's genesis across different spatio-temporal plateaus moving downwards, to the past (as this is the journey that I initiate in this chapter). Having first looked at the socio-cultural and political context in which the movie was created and released, I then proceed to examine its temporally expansive deep play of rebellion, resistance and anarchist chaos. By 'deep play' refer to the 
malleable context in which 'institutions, processes and social behaviours can be intelligibly described' (Geertz, 1973, p.14). Following here Philip Smith's (2011) masterful sociological repurposing of Geertzian theory as effective storytelling, I try to show that nothing is what it seems, that we must train ourselves in deciding when we must stay open and hopeful to the game of impressions and when we should quit. Such storytelling accommodates (a) the methodological thrill of solving a social puzzle, (b) the ability to connect miniature events and phenomena to grand themes, and (c) enlisting the emotional support of readers, thus committing them to follow the drama from start to finish. Through my journeys, I see how two of the principal forces of modernity, individual creativity (its socio-cultural dimensions) and statist or corporate bureaucracy (its political and economic ones), claim exclusive control over the realm of human experience. 